\title{
Study on Variable Action Value Standard for Harbor Infrastructures
}

\author{
Xiaoping Zhong and Qianyi Zhao \\ College of Civil Science and Engineering of Yangzhou University \\ Xiaoping Zhong and Weiliang Jin \\ Institute of Structural Engineering, Zhejiang University
}

\begin{abstract}
To meet with different levels of requirements from proprietors and users and to offer a basis for variable action value to the designers, associated with the standards, this dissertation studied the value standard of load effect and environmental effect. For load effect, on the foundation of analyzing variable load effect model, we used equal exceeding probability principle to calculate the load adjustment coefficient for the cargo loading in harbor and river port under different designing service life. For environmental effect, according to the ranks of marine chloride environment in standards GB/T 50476-2008, after analyzing and comparing the research achievements on surface chloride concentration at home and abroad, we obtained the value standard of chloride ion loading in different ranks of chloride environment.
\end{abstract}

\section{INTRODUCTION}

Whether or not a structure can meet with the demand of proprietors, users and society in the future are closely related to the effect level considered to impose on it when designing, that is the magnitude of effect. Usually, we use the value standard of variable effect to quantify the magnitude of effect. Using different standards of effect in designing, correspondingly, we get various performance levels for structure and various satisfaction levels for proprietors and users. Therefore, determination of structural effect standards is necessary for performance-based structural design.

The main effects imposed on harbor structures are load effect and environmental effect. Load effect controls the safety and applicability of structure, while environmental effect influences the structural durability, the insufficient of which may further affect the safety and applicability of structure. Current harbor structure designing mainly value the variable load according to the Code for Loads of Port Engineering, in which the value standards of variable load, wind load, and ice load are provided under the circumstance of 50-year designing service life. When the demand of proprietors and users differs from the 50-year designing service life, the code gives no corresponding value standard. Moreover, the durability problem caused by environmental effect, especially chloride environment, is particularly serious in harbor structures, which directly affects the service life of harbor structures. Hence, we must take it into serious consideration. However, to clarify the connection between harbor structure service life and its durability, one of the important tasks is to determine the value standard of environmental load. However, as the code of harbor structure has not included the value standard of environmental load yet, the designers' hands are tied on relative durability design. In view of the abovementioned factors, it has a really profound theoretical and practical meaning to carry out the research on the value standard of variable load of harbor structure under the circumstances of different designing service life and chloride attack.

\section{LOAD EFFECT STANDARDS FOR VARIOUS DESIGNING SERVICE LIFE}

2.1 Relationship between variable load standard value and design reference period

In the performance-based structural design, the standard value of variable load should be determined first, according to the requirement of proprietors and users, then the various performance indexes of components or the whole structure can be analyzed and calculated (Jin \& Zhong, 2009). Studies showed that with longer design reference period, it is more possible for the peak load to appear (Wang et al., 2009; Zhang, Gao, \& Li, 2000). That is to say, the variable load standard value changes with the design reference period. Current code for harbor loads provides the variable load standard value for 50 -year design reference period only. If the proprietors or users require a designing service life unequal to 50 years, using a 50-year design reference period, to determine the variable load standard value may be either conservative or insecure. Thus, performance-based 
design should consider the variable load value under the circumstances of different designing service life. This dissertation used the cargo loading in harbor as an example to study its variable load value standard for different design reference period.

\subsection{Model for variable load effect}

Determining variable load value standard according to different designing service life is equivalent to ranking the variable load into different levels, and loads for each level can be determined on the basis of existing model of variable loads. According to the stationary binomial random process model $\{Q(t), t \in[0, T]\}$ and relative hypothesis, the probability distribution function of peak load $Q_{T}$ in the design reference period $T$ is

$$
F_{\mathrm{QT}}(x)=\left[F_{\mathrm{Q}}(x)\right]^{m} .
$$

In this function, $m=p r$ is the average appearing time of loads in design reference period; $p$ is the probability for the loads appearance on each period.

If the probability distribution at any given time follows the extreme I distribution:

$$
\begin{gathered}
F_{\mathrm{Q}}(x)=\exp [-\exp (-\alpha(x-u))] . \\
u=\mu-0.5772 / \alpha . \\
\alpha=\frac{\pi}{\sqrt{6}} \frac{1}{\sigma} .
\end{gathered}
$$

In which, $u$ means mode; $\alpha$ is the scale parameter.

Variable load standard value is equal to some fractile on the peak load probability distribution for design reference period. The relationship among the peak load distribution, at any given time, the peak load distribution for design reference period, and the load standard value is shown in Figure 1.

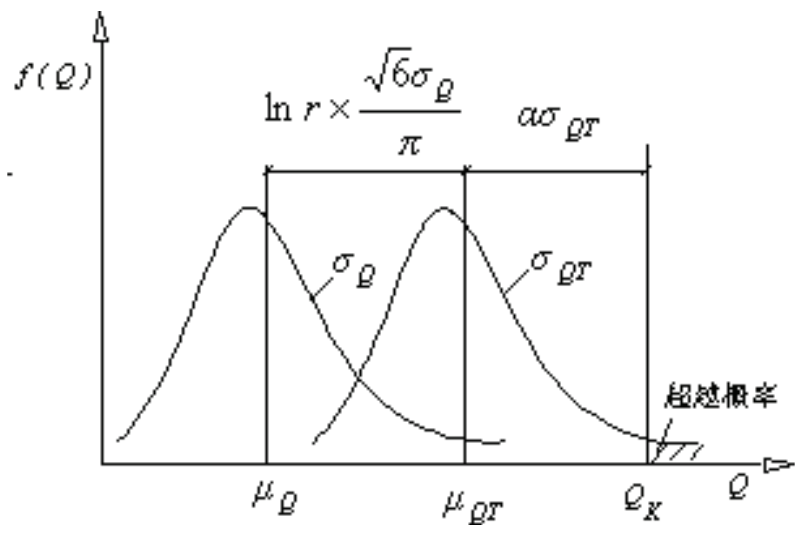

Figure 1. Relationship between any time point and design reference period of the biggest live load distributions.

Therefore, there is a relationship lied between the average value and standard deviation of load distribution in a certain design reference period $T$ and of load distribution at any given time:

$$
\begin{gathered}
\mu_{\mathrm{QT}}=\mu_{\mathrm{Q}}+\ln r \times \frac{\sqrt{6} \sigma_{\mathrm{Q}}}{\pi} \\
\sigma_{\mathrm{QT}}=\sigma_{\mathrm{Q}} .
\end{gathered}
$$

The relationship between the standard value of load and the assuring rate in design reference period $T$ is as follows:

$$
\begin{aligned}
p_{\mathrm{k}}=F_{\mathrm{QT}}\left(Q_{\mathrm{KT}}\right) & =\exp \left[-\exp \left(-\alpha\left(Q_{\mathrm{KT}}-u\right)\right)\right] . \\
Q_{\mathrm{KT}} & =u-\frac{1}{\alpha} \ln \left(-\ln \left(p_{\mathrm{k}}\right)\right) .
\end{aligned}
$$

which can be further simplified as the following:

$$
\begin{aligned}
Q_{\mathrm{KT}} & =\mu_{\mathrm{QT}}-0.45 \sigma_{\mathrm{QT}}-\frac{\ln \left(\ln \left(1 / p_{\mathrm{k}}\right)\right)}{1.28255} \sigma_{\mathrm{QT}} \\
& =\mu_{\mathrm{QT}}-\left[0.45+\frac{\ln \left(\ln \left(1 / p_{k}\right)\right)}{1.28255}\right] \sigma_{\mathrm{QT}} .
\end{aligned}
$$

In this function, $Q_{\mathrm{KT}}$ is the corresponding load standard value to design reference period $T ; \mu_{\mathrm{QT}}$, $\sigma_{\mathrm{QT}}$ are the average value and standard deviation of load distribution in reference period $T ; \mu_{\mathrm{Q}}, \sigma_{\mathrm{Q}}$ are the average value and standard deviation of load distribution at any given time; $r$ is the average change times of load in design reference period $T$.

\subsection{Determination of cargo loading standard value for different designing service life}

From the April of 1984 to the October of 1988, China has investigated and analyzed the cargo loading of three harbors in Shanghai, Tianjin, Dalian, and eight river ports in Changsha, Wuxi, Nanjing, Harbin, and so on. The statistical results show that the cargo loading follows the extreme I distribution (Drafting Group of Standard, 1992). In the current Code for Loads of Port Engineering (JTS144-1-2010), the design reference period for harbor cargo loading is 50 years. Cargo variable loading standard value is determined by $Q_{\mathrm{KT}}=\mu_{\mathrm{QT}}+2.0 \sigma_{\mathrm{QT}}$. Suppose that the distribution of $Q_{K T}$ also follows the extreme I distribution, the assuring rate for this is $95.8 \%$. To keep the loads assuring rate or the risk rate for different designing service life accord with current code, this dissertation used an identical assuring rate $98.5 \%$ as the setting level (also known as equal exceeding probability). According to the statistical information (Drafting Group of Standard, 1992), for different harbor types, under normal handing technology, the cargo loading standard value for different designing service life can be calculated by functions (5), (6), and (9). Considering that cargo loading standard value in the code should not change with the designing service life; thus, a loading adjustment coefficient $\gamma_{T}$ is used 
to amplify the effect of designed value of loads. $\gamma_{T}$ is determined as follows:

$$
\gamma_{\mathrm{T}}=\frac{Q_{K T}}{Q_{K, 50}} .
$$

In this function, $Q_{K, 50}$ is the load standard value that corresponds to 50 -year design reference period.

Using functions (9) and (10) can calculate the loads adjustment coefficient for harbor and river port in different designing service life. The calculation results are provided in Table 1. The values not shown in the table can be calculated by linear interpolation.

Table 1. Load adjustment coefficient of harbor/river port loading dock goods loads based on considering structure design service life.

\begin{tabular}{|c|c|c|c|c|c|}
\hline \multirow{2}{*}{$\begin{array}{l}\text { Designing } \\
\text { service } \\
\text { life/year }\end{array}$} & \multicolumn{2}{|c|}{$\gamma_{\mathrm{T}}$} & \multirow{2}{*}{$\begin{array}{l}\text { Designing } \\
\text { service } \\
\text { Life/Year }\end{array}$} & \multicolumn{2}{|c|}{$\gamma_{T}$} \\
\hline & Harbor & $\begin{array}{c}\text { River } \\
\text { port }\end{array}$ & & Harbor & $\begin{array}{c}\text { River } \\
\text { port }\end{array}$ \\
\hline 10 & 0.86 & 0.9 & 60 & 1.02 & 1.02 \\
\hline 20 & 0.92 & 0.94 & 70 & 1.03 & 1.03 \\
\hline 30 & 0.95 & 0.97 & 80 & 1.05 & 1.04 \\
\hline 40 & 0.98 & 0.99 & 90 & 1.06 & 1.05 \\
\hline 50 & 1.0 & 1.0 & 100 & 1.07 & 1.06 \\
\hline
\end{tabular}

In structural designing, the load effect for different designing service life can be obtained by multiplying the load effect calculated according to the code (50-year reference period) by the adjustment coefficient $\gamma_{T}$, as showed in function (11):

$$
S_{d}=\gamma_{0}\left(\gamma_{G} S_{G k}+\gamma_{Q} \gamma_{T} S_{Q k}\right) .
$$

In the function, $\gamma_{G}, \gamma_{Q}$ are the partial factors of permanent load and variable load; $\gamma_{0}$ is the structural importance factor.

\section{ENVIRONMENTAL EFFECT LEVEL AND EFFECT STANDARD}

\subsection{Environmental effect level}

The factors that can cause structure deterioration are of multiaspects. According to the corrosion mechanism of steel and concrete, Code for Durability Design of Concrete Structure (GB/T 50476-2008) of China divided the environment into five levels: normal environment, freeze-thaw environment, marine chloride environment, deicing salt and other chloride environment, and chemical corrosion environment. On the basis of environmental levels, the marine chloride environment is divided into four effect levels: C - medium, D - severe, E - very severe, and F - extreme severe. Detailed descriptions are also provided.
The effect level for chloride environment differs among the codes of countries. For example, the Eurocode2 (British Standards Institution [BSI], 2004) for Europe makes three effect levels for two kinds of chloride environments separately; the American Concrete Institute [ACl] Committee 318 (2008) for America divided the effect level into three kinds according to the requirements of protection of steel corrosion. Although various countries had their ranks of chloride environments, they did not provide the eigenvalues of environmental load corresponded to different environmental effect levels. Thus, the relationship between structure performance and the demand of proprietors is not clear enough. The designers can only obtain the durability performance requirement of materials according to the corresponding chloride environment effect level and the designing service life and then provide the construction measure, concluding minimum concrete cover, maximum water-cement ratio, and so on., that is to assure the durability of harbor structure from construction measures, which prevent the proprietors and users from precisely knowing how long can the structure last in the future. To build the quantitative relation for the performancebased harbor concrete structure durability ultimate limit state design, it is necessary to study the value standard of chloride corrosion loads.

\subsection{Determination of chloride corrosion load standard}

For the harbor structure in chloride environment, the diffusion of chloride ions is caused by the chloride concentration difference. The higher the surface chloride concentration is, the bigger the concentration difference is in and out, and more chloride ions will get into the concrete, steels will get corroded more easily, which will result in the deterioration of structural performance. Hence, the surface chloride concentration of concrete $C_{\mathrm{s}}$ can be taken as the environmental load.

The surface chloride concentration is mainly determined by local environmental condition, as well as the concrete quality, shape of the structure, and the exposed parts. As Fluge reported (Fluge, 2001), chloride ions' maximum concentration decreases with the rise of altitude above sea level. Parts with lower chloride concentration are mainly those who are exposed to the prevailing wind direction or be washed by sea water all the time. Chloride ions at these parts will be occasionally washed away by water and settle down somewhere secluded.

The discreteness and variability of surface chloride concentration for all the concrete structure are big (Odd, 2009). For newly built harbor concrete structures, when evaluating and choosing the chloride ion concentration, it is better to use the 
field investigation data of similar structures in similar environment conditions. When there is no field survey information, the normal experience in references can be used to choose an adequate chloride load.

Based on the immense investigation information on the concrete structure at Norway seashore, Odd (2009) gave a guidance of the discreet value of structure chloride concentration in severe marine environment. The data are showed in Table 2.

Table 2. Chloride ion load-estimated values of concrete structures in proposed severe ocean environment by odd.E.Gj $\phi r v$.

\begin{tabular}{lcc}
\hline Chloride load & \multicolumn{2}{c}{$C_{\mathbf{s}}$ (\%, for cement mass) } \\
\cline { 2 - 3 } & Average & Standard deviation \\
\hline High & $5.5(0.96)$ & 1.3 \\
Average & $3.5(0.61)$ & 0.8 \\
Medium & $3.5(0.61)$ & 0.3 \\
\hline
\end{tabular}

The values in brackets are the percentage of concrete mass. In the conversion, the mass of each cubic meter of concrete is 2300 and $400 \mathrm{~kg}$ for the binding material.

According to the 4600 chloride ions sampling analyses of Bridge Gims $\phi y$ Straumen in Norway and other 35 seashore bridges, Fluge (2009) divided four zones for chloride concentration, as showed in Table 3, in which the eigenvalue of surface chloride concentration $C_{\mathrm{sn}}=C_{\mathrm{s}}+1.3 \sigma_{\mathrm{s}}$

Table 3. Proposed surface chloride ion concentration values by fluge $(\%$, for concrete mass).

\begin{tabular}{ccccc}
\hline $\begin{array}{c}\text { Altitude above } \\
\text { sea level/m }\end{array}$ & $\begin{array}{c}\text { Average } \\
\text { value } \boldsymbol{C}_{\mathbf{s}}\end{array}$ & $\begin{array}{c}\text { Standard } \\
\text { deviation } \boldsymbol{\sigma}_{\mathbf{s}}\end{array}$ & $\begin{array}{c}\text { Eigenvalue } \\
\boldsymbol{C}_{\mathbf{s n}}\end{array}$ \\
\hline 1 & $0-3$ & 0.51 & 0.23 & 0.81 \\
2 & $3-12$ & 0.36 & 0.24 & 0.67 \\
3 & $12-24$ & 0.22 & 0.19 & 0.47 \\
4 & $>24$ & 0.17 & 0.10 & 0.30 \\
\hline
\end{tabular}

Val and Stewart (2003) suggested that the surface chloride load $C_{\mathrm{s}}$ in different environmental conditions should value according to Table 4 and take logarithmic normal distribution as the probability distribution.

Table 4. Proposed surface chloride ion concentration values by stewart (unit: $\mathrm{kg} / \mathrm{m}^{3}$ ).

\begin{tabular}{lcc}
\hline Environmental condition & $\begin{array}{c}\text { Average } \\
\text { value }\end{array}$ & $\begin{array}{c}\text { Variable } \\
\text { coefficient }\end{array}$ \\
\hline Splash zone & $7.35(1.28)$ & 0.70 \\
Offshore atmospheric environment & $2.95(0.51)$ & 0.70 \\
$0.1 \mathrm{~km}$ & & \\
$1 \mathrm{~km}$ Distant from seashore & $1.15(0.20)$ & 0.50 \\
\hline
\end{tabular}

The values in brackets are the percentage of concrete mass. In the conversion, the mass of each cubic meter of concrete is 2300 and $400 \mathrm{~kg}$ for the binding material.
Based on the exposure tests and investigations at engineering works, Wang, Tian, and Fan (2010) discovered that using fly ash and slag will increase surface chloride concentration. After statistical analysis, the concrete's maximum surface chloride concentration is provided in Table 5 .

Table 5. Proposed biggest surface chloride ion concentration values by Wang Shengnian and so on (\%, for concrete mass).

\begin{tabular}{lccc}
\hline Zones & $\begin{array}{c}\text { Atmospheric } \\
\text { zone }\end{array}$ & \multicolumn{2}{c}{$\begin{array}{c}\text { Splash zone/Tidal range } \\
\text { zone }\end{array}$} \\
\cline { 3 - 4 } & & $\begin{array}{c}\text { Portland } \\
\text { cement }\end{array}$ & $\begin{array}{c}\text { Fly ash cement/ } \\
\text { Slag cement }\end{array}$ \\
\hline North & 0.7 & 0.9 \\
Eastern China & 0.6 & 0.9 & 1.0 \\
Southern China & & 1.0 & 1.0 \\
\hline
\end{tabular}

In the concrete standard of JSCE published in 2002, the concrete surface chloride concentration values in offshore atmospheric zone were raised, as shown in Table 6 (CCES01, 2004). And the values used in American Life-365 (2000) standard design procedures were given in Table 7 .

Table 6. Surface chloride ion concentration of concrete in inshore atmospheric zone (Japan Society Civil Engineers; \%, for concrete mass).

\begin{tabular}{lccccc}
\hline Splash zone & \multicolumn{5}{c}{ Distance from seashore/km } \\
\cline { 2 - 6 } & $\begin{array}{c}\text { Around } \\
\text { coastline }\end{array}$ & $\mathbf{0 . 1}$ & $\mathbf{0 . 2 5}$ & $\mathbf{0 . 5}$ & $\mathbf{1 . 0}$ \\
\hline 0.65 & 0.45 & 0.225 & 0.15 & 0.1 & 0.075 \\
\hline Concentration in the table is the relative ratio to the mass of each cubic meter
\end{tabular}
of concrete (about $2300 \mathrm{~kg}$ ).

Table 7. Adopted surface chloride ion concentration of harbor engineering concrete in Life-365 design (\%, for concrete mass).

\begin{tabular}{lcc}
\hline Zones & $\begin{array}{c}\text { Accumulation } \\
\text { speed of surface } \\
\text { chloride/\%/year }\end{array}$ & $\begin{array}{c}\text { Maximum } \\
\text { surface chloride } \\
\text { concentration/\% }\end{array}$ \\
\hline Tidal range zone & Instant & 0.8 \\
Salt fog zone & 0.10 & 1.0 \\
800 m within & 0.04 & 0.6 \\
seashore & & 0.6 \\
1500 m within & 0.02 & \\
seashore & & \\
\hline
\end{tabular}

Concentration in the table is the relative ratio to the mass of each cubic meter of concrete (about $2300 \mathrm{~kg}$ ).

Bamforth (1994) suggested that the surface chloride concentration $C_{\mathrm{s}}$ used for design can take the values in Table 8 as reference. 
Table 8. Proposed surface chloride lon concentration $\mathrm{C}_{\mathrm{s}}$ for design by Bamforth (\%, for concrete mass).

\begin{tabular}{lcc}
\hline Environment & Portland cement & $\begin{array}{c}\text { Cement concrete } \\
\text { with admixtures }\end{array}$ \\
\hline Splash zone & $0.75(4.5)$ & $0.9(5.4)$ \\
Salt fog zone & $0.5(3.0)$ & $0.6(3.6)$ \\
Atmospheric zone & $0.25(1.5)$ & $0.3(1.8)$ \\
\hline
\end{tabular}

Values in brackets are the ratios for occupying the mass of binding material, approximately $400 \mathrm{~kg}$ binding material for each cubic meter of concrete.

Vu and Stewart studied about 1158 bridges and achieved the results that the surface chloride concentration $C_{\mathrm{s}}\left(\mathrm{kg} / \mathrm{m}^{3}\right)$ of concrete in seashore atmospheric environment is connected with its distance from coastline $d(\mathrm{~km})$, the value of which can be calculated by function (12):

$$
\left\{\begin{array}{lc}
C_{\mathrm{s}}(d)=2.95, & d<0.1 \\
C_{\mathrm{s}}(d)=1.15-1.81 \cdot \lg d, & 0.1<d<2.84 \\
C_{\mathrm{s}}(d)=0.03, & d>2.84
\end{array} .\right.
$$

Dura Crete of Europe thought that surface chloride concentration has a relationship with environmental conditions, water-cement ratio of concrete, and binding material type, of which the average value use function (13) to calculate, and the design value determined by function (14):

$$
\begin{aligned}
& C_{\mathrm{s}}=A_{\mathrm{cs}}(W / B) . \\
& C_{\mathrm{s}}=A_{\mathrm{cs}}(W / B) \cdot \gamma_{\mathrm{cs}} .
\end{aligned}
$$

In these function, $A_{c s}$ is the regression parameter describing the relationship between surface chloride concentration and water-cement ratio, whose value is provided in Duracrete (2000); $\gamma_{c s}$ is the partial coefficient of surface chloride concentration. According to the ratio between the expenses used to contain steel corrosion and the structure's repairing expense, the partial coefficient is determined as $1.70,1.40$, and
1.20, respectively corresponding to a higher, equal, and lower rate.

According to the maximum water-cement ratio requirement of concrete in chloride environment from our standard GB/T50476 (2008) and the calculation method given by Dura Crete, we used the conditions of water-cement ratio at 0.35 and 0.4 as two examples, to calculate the average value and design value of chloride concentration in different zones. The results are showed in Table 9.

Taken the studies of Odd (2009), Val and Stewart (2003), Wang et al. (2010), CCES01 (2004), Life365 (2000), Banforth (1994), Vv and Stewart (2000), and Duracrete (2000) together, there are mainly two directions. One is to divide regions along the altitude above sea level, so that underwater zone, tidal range zone, splash zone, atmospheric zone are partitioned; the other is to divide regions along the horizontal direction, according to the distance from coastline. Difference exists among the suggested value of surface chloride concentration from different references. But they share accordance with each other in the general trend, that is, the more corrosive the environment is, the higher surface chloride concentration will be a structure get. Surface chloride concentration in splash zone, tidal range zone is higher than atmospheric zone. With the increase of distance from coastline, surface chloride concentration decreases.

To determine the standard value of chloride concentration in different levels of chloride environment, this dissertation used the environmental levels in Code for Durability Design of Concrete Structure of China (GB/t 50476-2008) as standards. According to the detailed description of different zones, combining the results of Odd (2009), Val and Stewart (2003), Wang et al. (2010), CCES01 (2004), Life-365 (2000), Banforth (1994), Vv and Stewart (2000), and Duracrete (2000), considering that the surface chloride concentration is a kind of environmental effect, which

\begin{tabular}{|c|c|c|c|c|c|c|c|c|c|}
\hline \multirow[t]{3}{*}{ W/C } & \multirow[t]{3}{*}{ Environment } & \multicolumn{8}{|c|}{$C_{\mathrm{s}}(\%$ for concrete mass) } \\
\hline & & \multicolumn{4}{|c|}{ Average value } & \multicolumn{4}{|c|}{ Design value } \\
\hline & & $\begin{array}{c}\text { Portland } \\
\text { cement }\end{array}$ & Fly ash & Slag & $\begin{array}{l}\text { Silica } \\
\text { fume }\end{array}$ & $\begin{array}{l}\text { Portland } \\
\text { cement }\end{array}$ & Fly ash & Slag & $\begin{array}{l}\text { Silica } \\
\text { fume }\end{array}$ \\
\hline \multirow[t]{3}{*}{0.35} & Underwater zone & 0.63 & 0.66 & 0.31 & 0.76 & 0.88 & 0.92 & 0.43 & 1.06 \\
\hline & Splash/tidal range zone & 0.47 & 0.45 & 0.41 & 0.55 & 0.66 & 0.63 & 0.57 & 0.76 \\
\hline & Atmospheric zone & 0.16 & 0.27 & 0.19 & 0.20 & 0.22 & 0.38 & 0.27 & 0.28 \\
\hline \multirow[t]{3}{*}{0.40} & Underwater zone & 0.72 & 0.75 & 0.35 & 0.87 & 1.00 & 1.05 & 0.49 & 1.22 \\
\hline & Splash/tidal range zone & 0.54 & 0.52 & 0.47 & 0.63 & 0.76 & 0.73 & 0.66 & 0.87 \\
\hline & Atmospheric zone & 0.18 & 0.31 & 0.21 & 0.22 & 0.25 & 0.43 & 0.30 & 0.31 \\
\hline
\end{tabular}
should maintain a certain assurance rate, we suggest

Table 9. Calculated surface chloride ion concentration by adopting dura crete method in this article.

Mass of each cubic meter of concrete is $2300 \mathrm{~kg}$, for binding material is $400 \mathrm{~kg}$. The partial coefficient $\gamma_{\mathrm{cs}}=1.4$. 
Table 10. Proposed surface chloride ion load characteristic value in this article (\%, occupying mass of concrete).

\begin{tabular}{|c|c|c|c|c|c|}
\hline Environment & Effect level & Environmental condition & $\begin{array}{l}\text { Average } \\
\text { value } C_{\mathrm{s}}\end{array}$ & $\begin{array}{c}\text { Standard } \\
\text { deviation } \mathrm{n} \sigma_{s}\end{array}$ & $\begin{array}{c}\text { Eigenvalue } \\
c_{s n}=C_{s}+1.3 \sigma_{s}\end{array}$ \\
\hline \multirow[t]{5}{*}{$\begin{array}{l}\text { Marine chloride } \\
\text { environment }\end{array}$} & III-C & $\begin{array}{l}\text { Underwater and underearth zone: surrounded by } \\
\text { sea water or buried in the ground forever }\end{array}$ & 0.75 & 0.23 & 1.05 \\
\hline & III-D & $\begin{array}{l}\text { Atmospheric zone (light salt fog): atmospheric } \\
\text { zone more than } 15 \mathrm{~m} \text { above the average water } \\
\text { level; outdoor onshore environment more than } \\
100-300 \mathrm{~m} \text { away from the tide coastline }\end{array}$ & 0.25 & 0.2 & 0.5 \\
\hline & III-E & $\begin{array}{l}\text { Atmospheric zone (severe salt fog): atmospheric } \\
\text { zone above the average water level within } 15 \mathrm{~m} \text {; } \\
\text { outdoor onshore environment away from the tide } \\
\text { coastline within } 100 \mathrm{~m} \text { and above the sea level } \\
\text { within } 15 \mathrm{~m}\end{array}$ & 0.35 & 0.25 & 0.7 \\
\hline & & Tidal zone and splash zone, nonhot region & 0.6 & 0.3 & 1.0 \\
\hline & III-F & Tidal zone and splash zone, hot region & 0.6 & 0.8 & 1.7 \\
\hline
\end{tabular}

that the eigenvalue of concrete surface chloride load is $C_{\mathrm{sn}}=C_{\mathrm{s}}+1.3 \sigma_{\mathrm{s}}(90 \%$ assurance rate). In the meantime, the dissertation provided the eigenvalue of chloride load corresponding to different chloride environment levels in Table 10.

Since the surface chloride concentration has a large discreteness and variability, the suggested chloride load value should get further modification according to the future accumulation of statistical information for specific cases in our country. Anyhow, suggested value in the table provides the designers a foundation for the environment load value in performance-based durability design.

\section{CONCLUSION}

(1) This dissertation using the equal exceeding probability principle, combining with current standards, based on the analysis of the relationship between variable load and design reference period and the model of variable load effect, gave the load adjustment coefficient $\gamma_{\mathrm{T}}$ for harbor and river port in consideration of the structure's designing service life. This adjustment coefficient enables the proprietors and users to get a value standard of load corresponding to their requirements. With a simple form, it is easy to understand and apply.

(2) On the basis of existing research achievements, combining with the level division of chloride environment in GB/T 50476-2008, we provided the suggestion value standard of chloride load corresponding to different chloride environment levels. This value standard can be used as the foundation of environment load value in performance-based durability design.

(3) The accuracy of surface chloride concentration value depends on immense actual survey data. We suggest that the value standard of chloride load corresponding to different chloride environment effect should better get further modification on the basis of future survey information.

\section{ACKNOWLEDGMENTS}

This work was supported by the National Natural Science Funds Programs (51278444) and Technology Projects of Ministry of Transport (2011 328806 1110).

\section{REFERENCES}

American Concrete Institute (ACl) Committee 318. (2008). Building code requirements for structural concrete (ACl 318-08) and commentary (ACl318R-08). Detroit, MI: ACl.

British Standards Institution (BSI). (2004). Eurocode2 (EN1992): Part 1-1: General rules and rules for building. London: Author.

Banforth, P. B. (1994). Specification and design of concrete for the protection of reinforcement in chloride contaminated environments (pp. 249-258). Bournemouth: UK Corrosion and Eurocorr 94.

CCES01. (2004). Durability design and construction guidelines of concrete structures. Beijing: China Architecture \& Building Press.

Drafting Group of Standard. (1992). Reliability of port engineering structures. Beijing: China Communications Press.

DuraCrete. (2000). General guidelines for durability design and redesign. The European Union-Brite EuRam III, Research Project No. BE95-1347. Probabilistic performance based durability design of concrete structures. Document Report 15:109.

Fluge, F. (2001). Marine chlorides: A probabilistic approach to derive provisions for EN 206-1. In Proceedings, third workshop on service life design of concrete structures: From theory to standardisation, DuraNet, Troms $\phi$ (pp. 47-68). 
GB/T50476. (2008). Code for durability design of concrete structures. Beijing: China Architecture \& Building Press.

Jin, W. L., \& Zhong, X. P. (2009). Relationship of structural durability with structural safety and serviceability in whole life-cycle. Journal of Building Structures, 30(6), 1-7.

Life-365. (2000). Computer program for predicting the service life and life cycle costs of RC exposed to chloride, version 1.0.0.

Odd, E. G. (2009). Durability design of concrete structures in severe environments. Norway: Taylor \& Francis.

Val, D. V., \& Stewart, M. G. (2003). Life-cycle cost analysis of reinforced concrete structures in marine environments. Structural Safety, 25(4), 343-362.
Vv, K. A. T., \& Stewart, M. G. (2000). Structural reliability of concrete bridges including improved chloride-induced corrosion models. Structural Safety, 22(4), 313-333.

Wang, K., Lv, L. Y., Zhou, J. Z., et al (2009). Study on the variable load in 60-year design reference period. Construction \& Design for Project, (10), 19-21.

Wang, S. N., Tian, J. F., \& Fan, Z. H. (2010). Research on theory and method of service life prediction of marine concrete structures based on exposure test and filed investigation. China Harbour Engineering, 169(1).

Zhang, J. Z., Gao, D. X., \& Li, G. Q. (2000). Study on the variable load value of reliability evaluation for existing architectural structures. Industrial Construction, 30(12), 58-61. 